\title{
Chocolate Milk with Sucrose and Stevia Preference by Pre- and Post-Menopausal Women
}

\author{
Marta Regina Verruma-Bernardi ${ }^{1,2,3}$, Kiwon Lee ${ }^{4}$, Stephanie Qing Liu ${ }^{5}$, \\ Peter Lawrence Bordi Jr. ${ }^{*}$ \\ ${ }^{1}$ Center for Agrarian Sciences, Federal University of São Carlos, São Paulo, Brazil \\ ${ }^{2}$ The National Council for Scientific and Technological Development (CNPq), Brasilia, Brazil \\ ${ }^{3}$ São Paulo Research Foundation (FAPESP), Ribeirão Preto, Brazil \\ ${ }^{4}$ Department of Retail, Hospitality, and Tourism Management, University of Tennessee, Knoxville, USA \\ ${ }^{5}$ School of Hospitality Management, Pennsylvania State University, University Park, USA \\ ${ }^{6}$ Center for Food Innovation, School of Hospitality Management, Pennsylvania State University, University Park, \\ USA \\ Email: ${ }^{*}$ PLBJr@psu.edu
}

Received 19 May 2014; revised 23 June 2014; accepted 7 July 2014

Copyright (C) 2014 by authors and Scientific Research Publishing Inc.

This work is licensed under the Creative Commons Attribution International License (CC BY).

http://creativecommons.org/licenses/by/4.0/

\section{(c) (i) Open Access}

\section{Abstract}

The objective of this study was to evaluate and compare the preference of chocolate milk products sweetened with sucrose and stevia by pre- and post-menopausal women and to examine their concerns about bone health. Women panelists were divided into two groups according to age: premenopausal (from 18 to 47 years old) and post-menopausal (over 48 years old) and answered the frequency of white and chocolate milk consumption during a week and their concerns about bone health. For preference, five kinds of chocolate milk were used: 1) Non Sucrose Added [NSA] with stevia and NutraFlora $\left.{ }^{\circledR}, 2\right)$ NSA with stevia, 3) with sucrose and stevia, 4) with sucrose, stevia, and NutraFlora ${ }^{\circledR}$, and 5) control with sucrose. The results showed that both groups (pre- and postmenopausal women) prefer chocolate milk to white milk. Pre-menopausal women prefer the chocolate milk with NSA stevia and NutraFlora ${ }^{\circledR}$, while post-menopausal women prefer the chocolate milk NSA with stevia without NutraFlora ${ }^{\circledR}$. For comparisons between chocolate milk with sucrose and stevia vs. chocolate milk with sucrose and stevia and NutraFlora ${ }^{\circledR}$ and chocolate milk with sucrose vs. chocolate milk with sucrose and stevia, there were no visible differences between pre- and post-menopausal women. Both groups were concerned about bone health, fiber, and calories, and their concerns about which influenced their milk choices. Pre-menopausal women showed a greater positive impact on milk choice when being informed the amount of fibers in the sample than post-menopausal women. Therefore, this study suggests that milk sweetened with stevia needs to be produced as calcium resources without increasing calories.

\footnotetext{
${ }^{*}$ Corresponding author.
}

How to cite this paper: Verruma-Bernardi, M.R., Lee, K., Liu, S.Q. and Bordi Jr., P.L. (2014) Chocolate Milk with Sucrose and Stevia Preference by Pre- and Post-Menopausal Women. Food and Nutrition Sciences, 5, 1352-1358. 


\section{Keywords}

\section{Preference, Flavor, Calories, Sweeteners}

\section{Introduction}

Menopause begins between the ages of 45 - 55 for most women, when estrogen and progesterone levels decrease. Good nutrition plays significant roles in the health and quality of life of pre- and post-menopausal women. It is generally agreed that post-menopausal women should get enough vitamin, calcium, and fiber but reduce fat and calorie consumption. Milk is an excellent source of dietary calcium because it has a high concentration of calcium and the calcium in milk is excellently absorbed [1]. Milk, yogurt, and cheese are rich natural sources of calcium and are the major food contributors of this nutrient to people in the United States [2].

A study has indicated a late age-related decrease in calcium absorption in post-menopausal women in addition to the decline that occurs at menopause [3]. Post-menopausal women are calcium deficient and have increased bone turnover [4]. According to Recommended Dietary Allowances (RDAs), woman aged between 19 and 50 years should have about $1000 \mathrm{mg}$ of calcium per day and women aged over 50 years should consume $1200 \mathrm{mg}$ of calcium each day [2]. However the majority of women older than forty consume less than $600 \mathrm{mg} /$ day in the United States [5].

Hess et al. [6] related that novel functional fibers are increasingly used in food processing and effectively increase the fiber content of traditionally non-fibrous foods. Short-chain fructooligosaccharides (scFOS) is one such form of non-viscous, soluble fiber produced from sucrose via an enzymatic process. Chain length influences the texture and sweetness of this fiber type - the shorter the chain length, the sweeter the taste; therefore, scFOS frequently are used as sweetening agents.

Hess et al. [6] cited that fiber may increase satiety. Satiety effects also may be linked to colonic fermentation. Short-chain fructooligosaccharides (scFOS) are fermentable fibers that can be added to foods to influence these actions. Tahiri et al. [7] described that scFOSs may be more beneficial to calcium absorption in women who are in late menopause and investigated the long-term effect of a moderate daily dose (10 g) of scFOSs on intestinal calcium absorption in 12 post-menopausal women and suggest that scFOS may influence calcium absorption in the late post-menopausal phase. Van den Heuvel et al. [8] observed a positive effect of lactulose in women who had been going through menopause for $>5$ years.

Tranquilli et al. [9] suggest that adequate nutritional recommendations and supplements should be given before the menopause. While nutritional factors associate bone health in post-menopausal women, dietary supplementation may be indicated for the prophylaxis of osteoporosis. The USDA guidelines recommend 3 cups per day of fat-free or low-fat milk and milk products for adults [10]. Moreover, the guidelines suggest that added fats or sugars are best used to increase the palatability of nutrient dense foods, and list fat-free chocolate milk as an example.

Liking for sucrose (and for sweets in general) declined with age, with women showing more rapid decline [11].

A study has indicated a late age-related decrease in calcium absorption in post-menopausal women in addition to the decline that occurs at menopause [3]. Post-menopausal women are calcium deficient and have increased bone turnover [4].

Willett et al. [12] conducted an 8-year follow-up study with 88,751 women 34 to 59 years of age and found protective effect of dietary fiber. Specifically, this study provided evidences about adverse influence of fat intake and a protective effect of fiber consumption in middle-aged women on breast cancer incidence.

It is important for menopausal women to follow dietary guidelines. The American Dietetic Association suggests that women in their mid to late forties and older consume 200 calories less than they would normally consume to maintain their weight. Replacing sucrose with sweeteners in flavored milk can largely reduce calories content in milk [13]. There is a growing interest in low-calorie alternatives to sucrose and recent publications have shown a strong increase in the attention to extracts of the Stevia rebaudiana plant for its sweetening qualities [14].

Stevia component rebaudioside A has the most sweetness and the least off-tastes to human raters [15]. Rebiana is the common name for high-purity rebaudioside A, a natural non-calorie sweetener 200 - 300 times more 
potent than sucrose. It provides zero calories and has a clean, sweet taste with no significant undesirable taste characteristics [16].

Stevia leaves have functional and sensory properties superior to those of many other high-potency sweeteners, and are likely to become a major source of high-potency sweetener for the growing natural food market in the future [17]. Stevia is stable at the high temperatures and in aqueous solutions, and has no energy value [18].

Sucrose-sweetened beverages have recently received great attention in the field of diet-disease relations [19]. Therefore, substituting sucrose with low-calorie sweeteners may be an efficacious weight management strategy. And also the low-calorie flavored milk product will help increase milk consumption and calcium intake in preand post-menopausal women. The objective of this study was to evaluate the preference of chocolate milks sweetened with sucrose and stevia for pre- and post-menopausal women and to verify their concerns about bone health, especially for fiber, and calories of the intention to purchase milk.

\section{Materials and Methods}

\subsection{Chocolate Milk}

Treatments comprised five types of chocolate milk produced by Ingredion Incorporated ${ }^{\mathrm{TM}}$. The ingredients and nutritional information of chocolate milk samples are described in Table 1.

Four samples contain stevia - the sweetener high-intensity Enliten ${ }^{\circledR}$, which is a naturally low-calorie sweetener, obtained from the plant Stevia rebaudiana (Bert.) Bertoniand two samples contain NutraFlora ${ }^{\circledR}\left(\operatorname{scFOS}^{\circledR}\right)$ prebiotic fiber.

\subsection{Participants}

This study was conducted in PSU Center for Food Innovation (CFI). Panelists were recruited using the Surveygizmo and selected according to age and gender. Woman panelists were divided into two groups: pre-menopausal (from 18 to 47 years old) and post-menopausal (over 48 years old). A total of 300 panelists visited the sensory laboratory to evaluate products five milk.

\subsection{Sensory Analysis}

The panelists answered the frequency of white and chocolate-added milk consumption during a week. Each panelist received approximately $2 \mathrm{oz}$. of each sample at $40^{\circ} \mathrm{F}$ in a disposable into clear plastic cups numbered with 3-digit random codes. For preference, the milks were served in pairs, and the panelists indicated the preferred sample:

- (A) Non Sucrose Added [NSA] with stevia and NutraFlora ${ }^{\circledR}$ vs. (B) NSA with stevia.

- (C) with sucrose and stevia vs. (D) with sucrose, stevia, and NutraFlora ${ }^{\circledR}$.

- (E) Control sucrose vs. (C) with sucrose and stevia.

Results were analyzed using Compusense ${ }^{\circledR}$ Five software (Guelph, Ontario, Canada). Analysis of variance (ANOVA) was used to compare mean scores of each chocolate milk. This study was approved by the Institu-

Table 1. Nutritional information of five chocolate milks.

\begin{tabular}{|c|c|c|c|c|c|}
\hline \multicolumn{6}{|c|}{ Chocolate Milk } \\
\hline & $\begin{array}{c}\text { NSA with Stevia and } \\
\text { NutraFlora }{ }^{\circledR}\end{array}$ & $\begin{array}{c}\text { NSA } \\
\text { with Stevia }\end{array}$ & $\begin{array}{l}\text { With Sucrose and } \\
\text { Stevia }\end{array}$ & $\begin{array}{c}\text { Sucrose and } \\
\text { Stevia and NutraFlora }\end{array}$ & $\begin{array}{c}\text { Control } \\
\text { (Sucrose) }\end{array}$ \\
\hline & A & B & $\mathrm{C}$ & $\mathrm{D}$ & $\mathrm{E}$ \\
\hline Enliten $^{\circledR}(\%)$ & 0.0247 & 0.0247 & 0.015 & 0.015 & 0 \\
\hline NutraFlora $^{\circledR}(\%)$ & 1.4 & 0 & 0 & 1.4 & 0 \\
\hline Calories $^{*}$ & 90 & 90 & 110 & 120 & 110 \\
\hline Protein (g) ${ }^{*}$ & 8 & 8 & 8 & 8 & 8 \\
\hline Calcium (mg) ${ }^{* 1}$ & 300 & 300 & 300 & 300 & 300 \\
\hline Carbohydrate Total (g) ${ }^{*}$ & 17 & 14 & 21 & 24 & 21 \\
\hline Fiber Dietetic $(\mathrm{g})^{*}$ & 4 & 1 & 1 & 4 & 1 \\
\hline Fat $(\mathrm{g})^{*}$ & 0.5 & 0.5 & 0.5 & 0.5 & 0.5 \\
\hline
\end{tabular}

\footnotetext{
${ }^{*}$ Amount per serving $8 \mathrm{oz}$. (238 g); ${ }^{1}$ The daily value, the recommended daily intake of a nutrient, for calcium is $1000 \mathrm{mg}$.
} 
tional Review Board at a large Northeastern University.

\subsection{Questionnaires}

Also, they were asked about concerns: 1) on bone health: if one sample was proven to produce good bone health and the other had no health claim, would this influence their choice? 2) Fiber: if one sample was labeled as a good source of fiber and the other had no health claim, would this influence their choice? 3) Calories: if one sample has more less calories and the other sample has less calories, would this influence their choice?

\section{Results and Discussion}

\subsection{Sensory Analysis}

The results in Table 2 showed that both groups of women (pre- and post-menopausal) prefer chocolate milk to white milk, which supports that chocolate is the most popular milk flavor and represents a popular option among children and adults [20]. Then flavor is an important sensory attribute that interferes in preference for this kind of milk.

Results showed that more than $50 \%$ of pre-menopausal women consume white milk at least once in a week (Table 3). The post-menopausal group has more frequent consumption of milk since both white and chocolate milk are consumed three times a week. It was found that for frequency four or more the percentage is much higher for the white milk for the two groups.

Javoor [21] showed that women from post menopause group stages consumed milk daily. About half the pre-menopausal women consumed occasionally and only 15 percent consumed weekly whereas 35 percent of women did not consume at all.

Table 4 describes preference percentage of pre- and post-menopausal women for chocolate milk with different sweeteners. The comparison result for chocolate milk NSA with stevia and NutraFlora ${ }^{\circledR}: 1$ ) vs. chocolate milk NSA with stevia; 2) showed that pre-menopausal women prefer the milk with NutraFlora ${ }^{\circledR}$, while postmenopausal women prefer the milk without NutraFlora ${ }^{\circledR}$. In summing of the two groups was found that the milk chocolate NSA with stevia and NutraFlora ${ }^{\circledR}$ has been most accepted. Hess et al. [6] related that scFOS chain length influences the texture and sweetness of this fiber type the shorter the chain length, the sweeter the taste; therefore, scFOS frequently are used as sweetening agents.

Post-menopausal women mentioned more positive comments about flavor on chocolate milk NSA with stevia. On the other hand, pre-menopausal women showed quite opposite preference with more improvement on texture.

For comparison between chocolate milk with sucrose and stevia (C) vs. chocolate milk with sucrose and stevia and NutraFlora ${ }^{\circledR}$ (D), there was no visible difference between pre- and post-menopausal women. The posi-

Table 2. Pre- and post-menopausal women groupsliking rate for white and chocolate milk.

\begin{tabular}{cccc}
\hline \multicolumn{1}{c}{ Milk } & & & Women \\
\hline \multirow{2}{*}{ White } & Yes & Pre-Menopausal $(\mathrm{n}=174)$ & Post-Menopausal $(\mathrm{n}=126) \mathrm{n}(\%)$ \\
& No & $130(74.7)$ & $103(81.7)$ \\
& Yes & $44(25.3)$ & $23(18.3)$ \\
\multirow{2}{*}{ Chocolate } & No & $173(94.4)$ & $126(100.0)$ \\
& & $1(5.6)$ & $0(0.0)$ \\
\hline
\end{tabular}

Table 3. Consumptionfrequency of white and chocolate milk by pre- and post-menopausal women groups.

\begin{tabular}{|c|c|c|c|c|}
\hline \multirow[b]{2}{*}{ Frequency consumption (days per week) } & \multicolumn{2}{|c|}{ White milk n (\%) } & \multicolumn{2}{|c|}{ Chocolate milk n (\%) } \\
\hline & Pre-menopausal & Post-menopausal & Pre-menopausal & Post-menopausal \\
\hline 0 & $26(14.9)$ & $13(10.2)$ & $24(13.8)$ & $12(9.5)$ \\
\hline 1 & $54(31.1)$ & $16(13.0)$ & 99 (56.9) & $44(34.9)$ \\
\hline 2 & $25(14.4)$ & 14 (11.1) & 34 (19.5) & 24 (19.1) \\
\hline 3 & $11(6.3)$ & $33(26.1)$ & $16(9.2)$ & $36(28.6)$ \\
\hline More 4 & $58(33.3)$ & $50(39.6)$ & $1(0.6)$ & $10(7.9)$ \\
\hline (n) & 174 & 126 & 174 & 126 \\
\hline
\end{tabular}


Table 4. Preference percentagefor chocolate milk by pre- and post-menopausal women.

\begin{tabular}{|c|c|c|}
\hline \multirow[t]{2}{*}{ Women } & \multicolumn{2}{|c|}{ Chocolate Milk n (\%) } \\
\hline & NSA with Stevia and NutraFlora ${ }^{\circledR}$ & NSA with Stevia \\
\hline & A & B \\
\hline Pre $(n=60)$ & $39(65.0)$ & $21(35.0)$ \\
\hline \multirow[t]{3}{*}{ Post $(n=40)$} & $16(40.0)$ & $24(60.0)$ \\
\hline & Sucrose and Stevia & Sucrose, Stevia and NutraFlora ${ }^{\circledR}$ \\
\hline & $\mathrm{C}$ & $\mathrm{D}$ \\
\hline Pre $(n=51)$ & $26(51.0)$ & $25(49.0)$ \\
\hline \multirow[t]{3}{*}{ Post $(n=49)$} & $20(40.8)$ & $29(59.2)$ \\
\hline & Control-Sucrose & Sucrose and Stevia \\
\hline & $\mathrm{E}$ & $\mathrm{C}$ \\
\hline Pre $(n=63)$ & $23(36.5)$ & $40(63.5)$ \\
\hline Post $(n=37)$ & $15(40.5)$ & $22(59.5)$ \\
\hline
\end{tabular}

tive comments which most stood out in both sample were chocolate flavor and texture in sample with sucrose, stevia and NutraFlora $^{\circledR}$ (D). Studies about the satiating capacity of dairy products showed that texture is an important factor [22].

Observed when the added number of women independent of age with milk. The sample with sucrose, stevia and NutraFlora ${ }^{\circledR}$ obtained larger preference.

Milk products using stevia powder were highly acceptable up to $25 \mathrm{mg}$ and are low in calories as compared to the basic recipe which makes them suitable for consumption by diabetics [23].

For comparison between chocolate milk control with sucrose (E) vs. chocolate milk with sucrose and stevia (C), there was also no visible difference between pre- and post-menopausal women. The result showed that both groups apparently prefer the milk with stevia based on more positive comments and opinions for improvements as sweetness. Despite the study of Bartoshuk et al. [11] indicated the sweetness of the candy did not change with age, sweetness ratings were more variable for women of child-bearing age than for same-aged men. Moreover, taste is an important attribute that influences healthy product purchase, as related by Bogue \& Troy [24].

\subsection{Questionnaires}

When it was presented a sample that was proven to produce good bone health the answer indicated that this could influence the choice of both groups, since the results were similar (Table 5). However, pre-menopausal group had higher percentage of negative responses about influence of choice while the post-menopausal group had more positive responses. Sandler et al. [25] indicated that the effects of milk consumption in childhood and adolescence on bone density may manifest as higher bone density decades later in menopause.

For pre- and post-menopausal group, the responses indicated a greater positive influence when informed a good source of fibers in the sample (Table 6). Studies described by Bogue \& Troy [24] showed the evident that more frequent fiber consumption increased with age and the whole, participants had a positive opinion of fiber and fiber rich foods. They believed that the consumption of fiber provided them with various health benefits. Dourisseau et al. [26] described that the willingness of fiber consumption is even lower in a group of obese women aged 16 - 55 years old and low-income.

Both women groups have similar concern about calories (Table 7). Stevia is inexpensive and available to most consumers; thus, it has the potential to be widely used and may assist individuals in regulating their weight if it has a positive effect on caloric substitution [27].

\section{Conclusions}

It is important for menopausal women to consume enough calcium, fiber and limited fat. Milk is a good source of calcium, but, can be a source of calorie as well. One more concern is that women prefer chocolate milk, which contain higher calorie than white milk. Thus, chocolate milk with low calorie would be a desirable item for menopausal women. If chocolate milk contains fiber as well, it would be most desirable. This study devel oped ideas for using types of sweeteners that contain low calorie and fiber. Thus, this study examined acceptance of chocolate milk with sweetener by women.

The result of this study showed that both groups (pre- and post-menopausal women) prefer chocolate milk to 
Table 5. Pre- and post-menopausal women’s concerns for bone health.

\begin{tabular}{ccc}
\hline Answers & Pre-Menopausal $\mathrm{n}(\%)$ & Post-Menopausal $\mathrm{n}(\%)$ \\
\hline Yes & $129(74.1)$ & $99(78.6)$ \\
No & $36(20.7)$ & $15(11.9)$ \\
I'm Not Sure & $9(5.2)$ & $12(9.5)$ \\
(n) & 174 & 126 \\
\hline
\end{tabular}

Question: “if one sample was proven to produce good bone health and the other had no health claim, would this influence their choice?”.

Table 6. Pre- and post-menopausal women’s concerns for fiber.

\begin{tabular}{ccc}
\hline Answers & Pre-Menopausal $\mathrm{n}(\%)$ & Post-Menopausal $\mathrm{n}(\%)$ \\
\hline Yes & $124(71.3)$ & $79(62.7)$ \\
No & $38(21.8)$ & $12(26.2)$ \\
I'm Not Sure & $12(6.9)$ & $4(11.1)$ \\
(n) & 174 & 126 \\
\hline
\end{tabular}

Question: “if one sample was labeled as a good source of fiber and the other had no health claim, would this influence their choice?”.

Table 7. Pre- and post-menopausal women’s concerns for calories.

\begin{tabular}{ccc}
\hline Answers & Pre-Menopausal n (\%) & Post-Menopausal n (\%) \\
\hline Yes & $108(62.1)$ & $80(63.5)$ \\
No & $51(29.3)$ & $37(29.4)$ \\
I'm Not Sure & $15(8.6)$ & $9(7.1)$ \\
(n) & 174 & 126 \\
\hline
\end{tabular}

Question: "if one sample has more calories and the other sample has less calories, would this influence their choice?”.

white milk. Pre-menopausal women prefer chocolate milk NSA with stevia and NutraFlora ${ }^{\circledR}$, which contain fewer calories than other milk products with sucrose, and post-menopausal women prefer the chocolate milk NSA with stevia without NutraFlora ${ }^{\circledR}$, containing the lowest calorie among five products. When selecting milk products, both groups tended to be influenced by whether or not products are good sources of fiber and calcium. In addition, evidence on good bone health of milk also influenced their milk choice. Thus, the overall results showed that women, regardless of pre- or post-menopausal, consider calories and bone health when choosing milk. Milk with sweetener, especially NutraFlora supplying fiber, may satisfy all women's concerns. The dairy industry can be tight in increasing fiber and calcium, and in decreasing calorie by using NutraFlora. This study suggests that milk with sweetener needs to be produced in order to solve concerns about calories and to increase milk consumption. Also, such milk items will give more functionality as sources of calcium and fiber.

\section{Acknowledgements}

This study was funded by Ingredion Corporate ${ }^{\mathrm{TM}}$. However, analysis and final results of this study were not influenced by representatives of the company. Sensory software was funded by a grant from Compusense Five.

\section{References}

[1] Weaver, C. (2006) Calcium. In: Bowman, B.A. and Russell, R.M., Eds., Present Knowledge in Nutrition, 9th Edition, ILSI Press, Washington DC.

[2] Committee to Review Dietary Reference Intakes for Vitamin D and Calcium, Food and Nutrition Board, Institute of Medicine (2010) Reference Intakes for Calcium and Vitamin D. National Academy Press, Washington DC.

[3] Nordin, B.E., Need, A.G., Morris, H.A., O’Loughlin, P.D. and Horowitz, M. (2004) Effect of Age on Calcium Absorption in Postmenopausal Women. The American Journal of Clinical Nutrition, 80, 998-1002.

[4] Qureshi, H.J., Hussain, G., Jafary, Z.A., Bashir, M.U., Latif, N., et al. (2010) Calcium Status in Premenopausal and Postmenopausal Women. Journal of Ayub Medical College Abbottabad, 22, 143-145.

[5] National Institutes of Health, Office of Dietary Supplements (2011) Calcium: Dietary Supplement Fact Sheet for Health Professionals. Washington DC.

[6] Hess, J.R., Birkett, A.M., Thomas, W. and Slavin, J.L. (2011) Effects of Short-Chain Fructooligosaccharides on Satiety 
Responses in Healthy Men and Women. Appetite, 56, 128-134. http://dx.doi.org/10.1016/j.appet.2010.12.005

[7] Tahiri, M., Tressol, J.C., Arnaud, J., Bornet, F.R.J., Bouteloup-Demange, C., et al. (2003) Effect of Short-Chain Fructooligosaccharides on Intestinal Calcium Absorption and Calcium Status in Postmenopausal Women: A Stable-Isotope Study. American Journal of Clinical Nutrition, 77, 449-457.

[8] Van den Heuvel, E.G.M., Schaafsma, G., Muys, T. and Van Dokkum, W. (1998) Nondigestible Oligosaccharides Do Not Interfere with Calcium and Nonheme Iron Absorption in Young, Healthy Men. American Journal of Clinical Nutrition, 67, 445-451.

[9] Tranquilli, A., Lucino, E., Garzetti, G. and Romanini, C. (1994) Calcium, Phosphorus and Magnesium Intakes Correlate with Bone Mineral Content in Postmenopausal Women. Gynecological Endocrinology, 8, 55-58. http://dx.doi.org/10.3109/09513599409028459

[10] US Department of Agriculture, US Department of Health and Human Services (2010) Dietary Guidelines for Americans (Chapter 4). www.dietaryguidelines.gov

[11] Bartoshuk, L.M., Marino, S.E. and Snyder, D.J. (2007) Age and Hormonal Effects on Sweet Taste and Preference. Appetite, 49, 277. http://dx.doi.org/10.1016/j.appet.2007.03.029

[12] Willett, W.C., Hunter, D.J., Stampfer, M.J., Colditz, G., Manson, J.E., et al. (19920 Dietary Fat and Fiber in Relation to Risk of Breast Cancer: An 8-Year Follow-Up. JAMA, 268, 2037-2044. http://dx.doi.org/10.1001/jama.1992.03490150089030

[13] Nall, R. (2011) Diet and Nutrition for Post-Menopausal Women. http://www.livestrong.com/article/465962-diet-nutrition-for-post-menopausal-women/

[14] Guggisberg, D., Piccinali, P. and Schreier, K. (2011) Effects of Sugar Substitution with Stevia, Actilight ${ }^{\mathrm{TM}}$ and Stevia Combinations or Palatinose ${ }^{\mathrm{TM}}$ on Rheological and Sensory Characteristics of Low-Fat and Whole Milk Set Yoghurt. International Dairy Journal, 21, 636-644. http://dx.doi.org/10.1016/j.idairyj.2011.03.010

[15] Sclafani, A., Bahran, M., Zukerman, S. and Ackroff, K. (2010) Stevia and Saccharin Preferences in Rats and Mice. Chemical Senses, 35, 433-443. http://dx.doi.org/10.1093/chemse/bjq033

[16] Prakash, I., DuBois, G.E., Clos, J.F., Wilkensa, K.L. and Fosdick, L.E. (2008) Development of Rebiana, a Natural, Non-Caloric Sweetener. Food and Chemical Toxicology, 46, S75-S82. http://dx.doi.org/10.1016/j.fct.2008.05.004

[17] Goyal, S.K., Samsher and Goyal, R.K. (2010) Stevia (Stevia rebaudiana) a Bio-Sweetener: A Review. International Journal of Food Sciences and Nutrition, 61, 1-10. http://dx.doi.org/10.3109/09637480903193049

[18] Figlewicz, D.P., Ioannou, G., Bennett, J., Kittleson, S., Savard, C. and Roth, C.L. (2009) Effect of Moderate Intake of Sweeteners on Metabolic Health in the Rat. Physiology \& Behavior, 98, 618-624. http://dx.doi.org/10.1016/j.physbeh.2009.09.016

[19] Niknam, M., Saadatnia, M., Shakeri, F., Keshteli, A.H. and Esmaillzadeh, A. (2013) Consumption of Sugar-Sweetened Beverages in Relation to Stroke: A Case-Control Study. International Journal of Food Sciences and Nutrition, 64, 1-6. http://dx.doi.org/10.3109/09637486.2012.694850

[20] Thompson, J.L., Drake, M.A., Lopetcharat, K. and Yates, M.D. (2004) Preference Mapping of Commercial Chocolate Milks. Journal of Food Science, 69, S406-S413. http://dx.doi.org/10.1111/j.1365-2621.2004.tb09958.x

[21] Javoor, D.B. (2006) Nutritional Status of Pre, Peri and Post Menopausal Women. M.HSc Thesis, University Library, University of Agricultural Sciences, Dharwad.

[22] Hogenkamp, P.S., Stafleu, A., Mars, M., Brunstrom, J.M. and De Graaf, C. (2011) Texture, Not Flavor, Determines Ex- pected Satiation of Dairy Products. Appetite, 57, 635-641. http://dx.doi.org/10.1016/j.appet.2011.08.008

[23] Agarwal, V., Kochhar, A. and Sachdeva, R. (2010) Sensory and Nutritional Evaluation of Sweet Milk Products Prepared Using Stevia Powder for Diabetics. EthnoMed, 4, 9-13.

[24] Bogue, J. and Troy, A.J. (2008) Consumers' Attitudes to Dietary Fibre and the Market Potential for a Beta-Glucan Enriched Food Product. Agribusiness Discussion Paper 49, Department of Food Business and Development, University College, Cork.

[25] Sandler, R.B., Slemenda, C.W., LaPorte, R.E., Cauley, J.A., Schramm, M.M., et al. (1985) Postmenopausal Bone Density and Milk Consumption in Childhood and Adolescence. The American Journal of Clinical Nutrition, 42, $270-274$.

[26] Dourisseau, D., Fawcett, T., Mobley, S. and Remley, D.P. (2012) “Going Grain”: Using Social Marketing to Promote Intake of Fiber-Rich Foods at Choice Pantries in Food Deserts. http://www.denadietetics.com/uploads/1/1/4/9/11491174/food_desert_grant_proposal.pdf

[27] Anton, S.D., Martin, C.K., Han, H., Coulon, S., Cefalu, W.T., et al. (2010) Effectsof Stevia, Aspartame, and Sucrose on Food Intake, Satiety, and Postprandial Glucose and Insulin Levels. Appetite, 55, 37-43. http://dx.doi.org/10.1016/j.appet.2010.03.009 
Scientific Research Publishing (SCIRP) is one of the largest Open Access journal publishers. It is currently publishing more than 200 open access, online, peer-reviewed journals covering a wide range of academic disciplines. SCIRP serves the worldwide academic communities and contributes to the progress and application of science with its publication.

Other selected journals from SCIRP are listed as below. Submit your manuscript to us via either submit@scirp.org or Online Submission Portal.
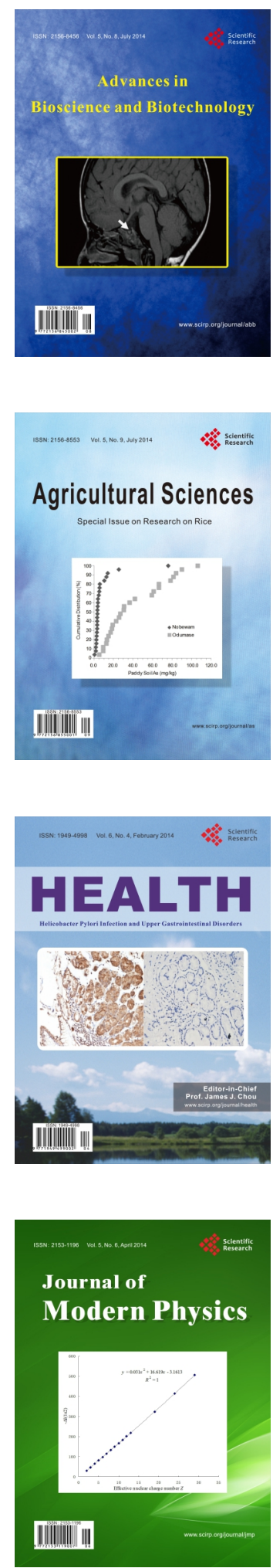
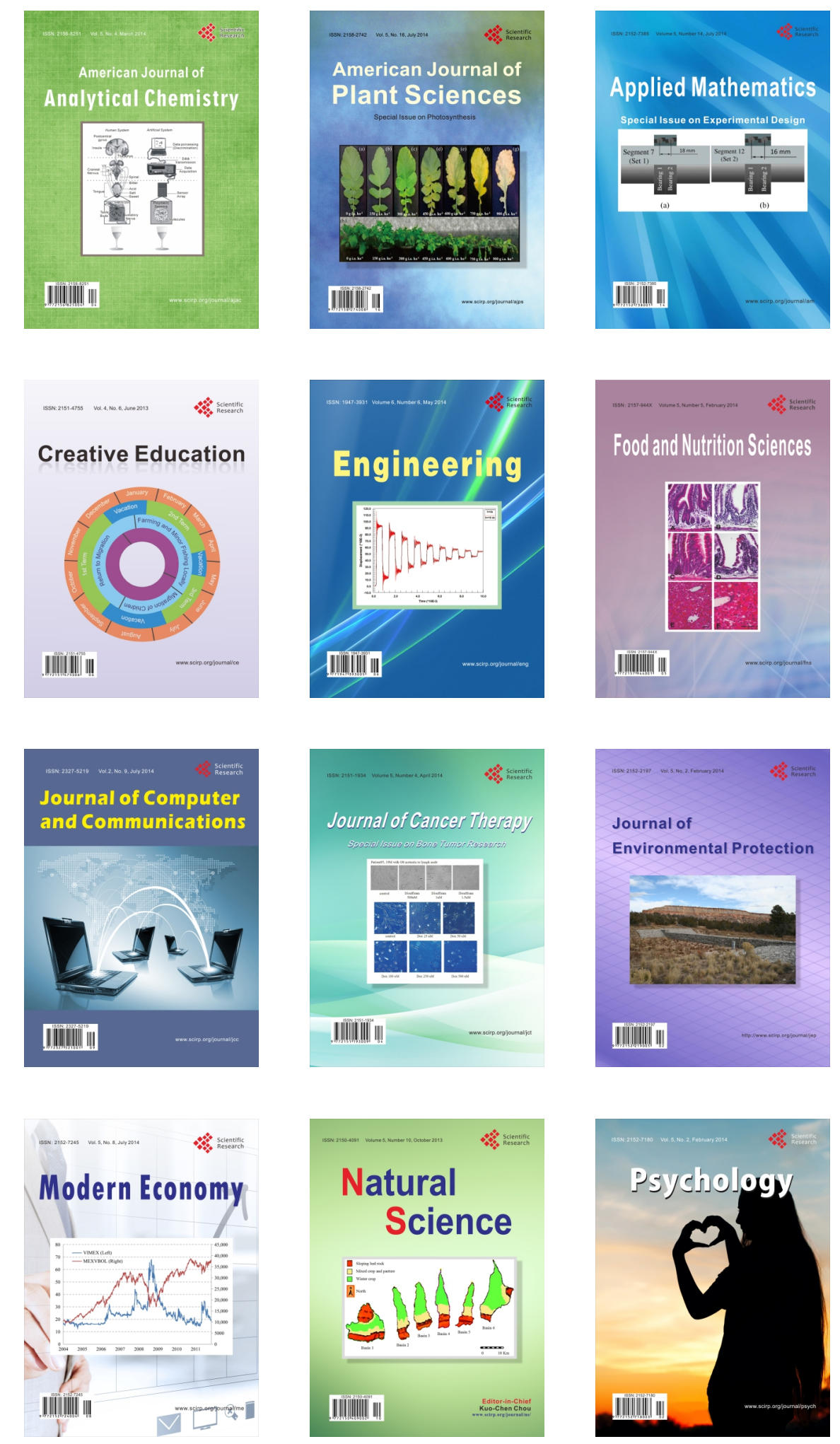